\title{
Detección de IgG anti Toxocara canis en perros de la Provincia de Corrientes, Argentina
}

\author{
García, L.D.'; López, M.²; Bojanich, M.V.'; Laffont, H.M.'; Alonso, J.M. ${ }^{2}$
}

${ }^{1}$ Cátedra de Inmunología, Facultad de Ciencias Veterinarias, Universidad Nacional del Nordeste, Corrientes, Argentina. ${ }^{2}$ Área de Inmunología, Instituto de Medicina Regional de la UNNE, Av. Las Heras 727,

Resistencia (3500), Provincia de Chaco, Argentina. E-mail: ecnomartin@hotmail.com.

\begin{abstract}
Resumen
García, L.D.; López, M.; Bojanich, M.V.; Laffont, H.M.; Alonso, J.M.: Detección de IgG anti Toxocara canis en perros de la Provincia de Corrientes, Argentina. Rev. Vet. 23: 1, 69-70, 2012. Toxocara canis es un nematode de los caninos, miembro de la familia Ascarididae, que accidentalmente infesta al hombre. Los cachorros expulsan los huevos con las heces a partir de la cuarta semana de vida. Con relación a la infestación humana, la mayoría de los trabajos realizados en nuestro país apuntan a determinar el grado de contaminación de los suelos. El propósito de esta investigación fue determinar con técnicas inmunológicas la prevalencia de infestación por $T$. canis en perros de localidades del interior de la Provincia de Corrientes, seleccionándose para el estudio los pueblos de San Lorenzo, San Roque y El Sombrero. Cuarenta y seis perros fueron estudiados mediante el test de ELISA indirecto para detección de anticuerpos de tipo IgG específicos para T. canis. El análisis reveló que el 86,95\% de los canes acusó serología positiva para este parásito. No se encontraron datos publicados sobre prevalencia de toxocariosis en poblaciones caninas de origen rural en Argentina. Los resultados alertan sobre la necesidad de implementar medidas de control de la infestación en perros para contribuir a la disminución del riesgo de transmisión al hombre.
\end{abstract}

Palabras clave: canino, Toxocara canis, serología, prevalencia, Argentina.

\begin{abstract}
García, L.D.; López, M.; Bojanich, M.V.; Laffont, H.M.; Alonso, J.M.: Detection of IgG anti Toxocara canis in dogs from Corrientes Province, Argentina. Rev. Vet. 23: 1, 69-70, 2012. Toxocara canis is a nematode of canines, member of the Ascarididae family, which accidentally infests humans. Puppies expel the eggs with the feces from the fourth week of life. For human infestation, most researches in Argentina are focused to determine the extent of soil contamination. The purpose of this study was to determine the prevalence of T. canis infestation in dogs from rural areas of the Province of Corrientes. El Sombrero, San Lorenzo and San Roque were the locations selected for the study. Indirect ELISA test was performed for detection of specific IgG antibodies to T. canis. Forty six dogs were studied. The analysis revealed that $86.95 \%$ of the dogs had positive serology for this parasite. There are no published data regarding the prevalence of infestation in dog populations from rural areas of Argentina. These results suggest the need to implement measures to control infestation in dogs thus contributing to reduce the risk of transmission to humans.
\end{abstract}

Key words: dog, Toxocara canis, serology, prevalence, Argentina.

\section{INTRODUCCIÓN}

Toxocara canis es un nematode de los caninos, miembro de la familia Ascarididae, que accidentalmente infesta al hombre. Los perros y otros cánidos silvestres pueden infestarse por ingestión de huevos existentes en el suelo, por ingestión de tejidos de huéspedes paraténicos contaminados con larvas, por migración transplacentaria de larvas de la hembra preñada a sus fetos o por ingestión de larvas con la leche por pasaje transmamario ${ }^{5}$.

Recibido: 9 abril 2012 / Aceptado: 2 mayo 2012
La infestación prenatal de cachorros ocurre cuando las larvas de la madre migran a través de la placenta. Las larvas permanecen en el hígado de los cachorros hasta el nacimiento, momento en que pasan a los pulmones, alcanzan la tráquea y maduran en intestino. Los huevos se expulsan con las heces a partir de la cuarta semana de vida ${ }^{5}$.

Debido a que el suelo juega un rol muy importante en la diseminación de esta zoonosis parasitaria, la mayoría de los trabajos realizados en Argentina apuntan a determinar el grado de contaminación de los suelos con huevos de Toxocara sp, principalmente en plazas y parques públicos. Al respecto, estudios de heces caninas 
presentes en aceras de la ciudad de Corrientes determinaron prevalencias de hasta un $16 \%{ }^{7}$, mientras que los análisis de suelos en la ciudad de Resistencia arrojaron valores que oscilaban entre 25 y 33,3\% de contaminación parasitaria ${ }^{1,6}$. En las ciudades de Mar del Plata ${ }^{2}$ y La Plata ${ }^{4}$, los muestreos de suelos registraron valores de prevalencia de 22,22 y $13,3 \%$ respectivamente.

Numerosos trabajos realizados en distintas ciudades con datos de contaminación en suelos de espacios públicos así como en materia fecal canina, alertan sobre la diseminación de este parásito. Sin embargo pocos tratan sobre la contaminación ambiental en zonas rurales y menos aún sobre la seroprevalencia en perros.

El propósito de este trabajo fue determinar la prevalencia serológica de infestación por Toxocara canis en caninos de áreas rurales de la Provincia de Corrientes.

\section{MATERIAL Y MÉTODOS}

Por venopunción cefálica se obtuvieron muestras de sangre de 46 perros de ambos sexos, diferentes razas y edades comprendidas entre 7 meses y 12 años (media 2,5 años), oriundos de las localidades de El Sombrero, San Lorenzo y San Roque (Provincia de Corrientes, Argentina). Los canes fueron llevados por sus dueños a jornadas de castración programadas en cada localidad.

Con el suero se realizó el test de ELISA indirecto para detección de anticuerpos de tipo IgG específicos para $T$. canis, empleando antígenos de excreción/ secreción de larvas L2, y anticuerpos anti IgG canina marcados con peroxidasa. Se empleó el test de Chi cuadrado para comparación de proporciones, empleando el software EpiInfo versión 6.0, considerando el valor de $\mathrm{p}<0,05$ como estadísticamente significativo.

\section{RESULTADOS}

Como indica la Tabla 1, el test ELISA indirecto reveló que el 86,95\% de los canes reveló serología positiva para T. canis. Al agruparlos por franja etaria, se encontró la mayor prevalencia en el rango de 1 a 3 años $(94,4 \%)$ siendo $80 \%$ en los menores de un año y $84,6 \%$ en los mayores de 3 años, aunque las diferencias no fueron significativas $(p=0,45)$. Con respecto a la zona de procedencia, la mayor prevalencia se encontró en la localidad de El Sombrero (100\% de positividad, $\mathrm{n}=12)$.

\section{DISCUSIÓN}

Existen muchos trabajos publicados sobre seroprevalencia de toxocariosis en población humana de zonas rurales. Refiriendo al área del Cono Sur de América se pueden mencionar datos tan variables que van desde un $78 \%$ de positividad en un población pediátrica rural de Paraguay ${ }^{9}$, hasta valores de 23 y $26,8 \%$ en comunidades rurales de Argentina y Brasil respectivamente ${ }^{3,10}$. Sin embargo, no se encontraron datos publicados sobre prevalencia de infestación en poblaciones caninas de origen rural.
Tabla 1. Seroprevalencia de toxocariosis según franja etaria.

\begin{tabular}{lcccc}
\hline \multirow{2}{*}{ edad } & \multicolumn{3}{c}{$\mathrm{n}$} & \multirow{2}{*}{ seropositividad } \\
\cline { 2 - 4 } & hembras & machos & total & \\
\hline menores de 1 año & 15 & 0 & 15 & $12 / 15-80,0 \%$ \\
de 1 a 3 años & 16 & 2 & 18 & $17 / 18-94,4 \%$ \\
mayores de 3 años & 11 & 2 & 13 & $11 / 13-84,6 \%$ \\
\hline
\end{tabular}

Los resultados obtenidos en el presente trabajo son similares a valores de seroprevalencia reportados en caninos de zonas urbanas de Brasil $(82,7 \%)^{8}$. Basándonos en estos datos, puede inferirse que la alta seroprevalencia encontrada en caninos de áreas rurales podría atribuirse a una pobre sanidad, carencia de desparasitaciones periódicas y falta de un correcto control veterinario. Tal situación aconseja la implementación de medidas de control de la infestación en perros para contribuir a la disminución del riesgo de transmisión al hombre.

\section{REFERENCIAS}

1. Alonso JM, Stein M, Chamorro MC, Bojanich MV. 2001. Contamination of soils with eggs of Toxocara in a subtropical city in Argentina. J Helminthol 75: 165-168.

2. Andresiuk MV, Denegri GM, Esardella NH, Hollmann P. 2003. Encuesta coproparasitológica canina realizada en plazas públicas de la ciudad de Mar del Plata, Buenos Aires, Argentina. Parasitol Latinoam 58: 17-22.

3. Chiodo P, Basualdo J, Ciarmela L, Pessani B, Apezteguía M, Minvielle M. 2006. Related factors to human toxocariasis in a rural community of Argentina. Mem Inst Oswaldo Cruz 101: 397-400.

4. Fonrouge R, Guardis MV, Radman NE, Archelli SM. 2000. Contaminación de suelos con huevos de Toxocara $s p$ en plazas y parques públicos de la ciudad de La Plata, Buenos Aires, Argentina. Bol Chil Parasitol 55: 3-4.

5. Gillespie SH, Bidwell D, Voller A, Robertson BD, Maizels RM. 1993. Diagnosis of human toxocariasis by antigen capture enzyme linked immunosorbent assay. J Clin Pathol 46: 551-554.

6. Luna AC, Alonso JM. 2004. Toxocara sp en plazas y parques de la ciudad de Resistencia, un riesgo latente. Anales Reunión Comunicac Científy Tecn UNNE, Corrientes, Argentina, resumen M-050.

7. Milano AM, Oscherov EB. 2005. Contaminación de aceras con enteroparásitos caninos en Corrientes, Argentina. Parasitol Latinoam 60: 82-85.

8. Regis SC, Mendonça LR, Silva S, Dattoli VC, Alcântara-Neves NM, Barrouin-Melo SM. 2011. Seroprevalence and risk factors for canine toxocariasis by detection of specific IgG as a marker of infection in dogs from Salvador, Brazil. Acta Trop 120: 46-51.

9. Rivarola CM, Vuyk AI, Riveros MM, Canese A, Micó VG. 2009. Toxocara canis en población pediátrica rural. Pediatr (Asunción) 36: 122-126.

10. Rubinsky-Elefant G, Da Silva M, Malafronte RS, Pascoal TM, Ferreira MU. 2008. Human toxocariasis in rural brazilian Amazonia: seroprevalence, risk factors, and spatial distribution. Am J Trop Med Hyg 79: 93-98. 